\title{
Perencanaan Pembangunan Kawasan Ekowisata Taman Buah Jeru Kabupaten Malang (Studi di Dinas Pariwisata dan Kebudayaan Kabupaten Malang)
}

\author{
Titik Wiyanti ${ }^{a^{*}}$ \\ ${ }^{a}$ Inspektorat Daerah Kabupaten Malang, Jawa Timur, Indonesia
}

\section{INFORMASI ARTIKEL}

\section{Article history:}

Dikirim tanggal: 22 Maret 2021

Revisi pertama tanggal: 26 Maret 2021

Diterima tanggal: 29 Maret 2021

Tersedia online tanggal: 14 April 2021

Keywords: the development planning, ecotourism area, local government

\section{ABSTRACT}

This research aims to analyse the development planning of the area of the Jeru Fruit garden in Malang District (study at the Tourism and Culture Office of Malang District). Researchers analyzed development planning using 6 (six) components, namely The decision to adopt planning, collect and analyse data, identyfing alternatives course of action, plan and project appraisal, implement, and monitoring and evaluation. The type of research used is descriptive research with a qualitative approach. The results of the research show that development planning is seen from 6 (six) components, that the implementation of the ecotourism area of Jeru Fruit Park in Malang district has been more than 4 (four) years but in fact there are still many activities have not been carried out optimally, such as the many physical results of development that has been completed but still not be utilized because of the lack of management certainty that can generate income as a source of Original Local Government Revenue.

\section{INTISARI}

Penelitian ini bertujuan untuk menganalisis Perencanaan Pembangunan Kawasan Ekowisata Taman Buah Jeru Kabupaten Malang (studi di Dinas Pariwisata dan Kebudayaan Kabupaten Malang). Peneliti menganalisa Perencanaan Pembangunan menggunakan enam komponen, yaitu The decision to adopt planning; Collect and analyse data; Identifying alternatives course of action; Plan and project appraisal, Implement; dan Monitoring and evaluation. Jenis penelitian yang digunakan adalah penelitian deskriptif dengan pendekatan kualitatif. Hasil penelitian menunjukkan, perencanaan pembangunan dilihat dari enam komponen, bahwa pelaksanaan pembangunan kawasan ekowisata Taman Buah Jeru di Kabupaten Malang sudah lebih dari empat tahun tetapi pada kenyataannya masih banyak kegiatan yang belum dilaksanakan secara optimal, seperti masih banyaknya hasil fisik pembangunan yang telah selesai dilaksanakan namun masih belum dapat dimanfaatkan karena belum adanya kepastian pengelolaan yang dapat menghasilkan pemasukan sebagai sumber Pendapatan Asli Daerah (PAD).

2021 FIA UB. All rights reserved.

\section{Pendahuluan}

Perencanaan pembangunan daerah meliputi seluruh sektor termasuk sektor pariwisata. Pembangunan pariwisata dinilai menjadi salah satu sektor yang dapat memberikan kontribusi besar terhadap sumber pendapatan dan peningkatan kesejahteraan masyarakat didaerah. Namun menurut Ramly (2007, h. 19) 
pembangunan kepariwisataan harus memiliki keterkaitan dengan lingkungan hidup yang berfokus pada pengelolaan sumber daya alam dan sumber daya manusia, yang merupakan fenomena yang tidak dapat dipungkiri. Pembangunan dan perlindungan lingkungan senantiasa saling melengkapi dalam mewujudkan ekosistem lingkungan yang seimbang, serasi, dan lestari, serta memiliki daya adaptasi lingkungan yang seimbang dan proporsional untuk memberi manfaat bagi lingkungan manusia.

Ide dasar dari pembangunan pariwisata adalah pembangunan berkelanjutan, yaitu kelestarian sumberdaya alam dan budaya adalah hal yang dibutuhkan setiap orang untuk menjalani kehidupan yang kaya, namun harus dijaga dan dilestarikan agar dapat dimanfaatkan di masa depan. Ide-ide ini kemudian diturunkan dalam konsep pariwisata berkelanjutan artinya adalah pembangunan sumberdaya pariwisata yang bertujuan untuk memberikan keuntungan optimal bagi pemangku kepentingan (stakeholders) dan nilai kepuasan optimal bagi wisatawan jangka panjang (Damanik \& Weber, 2006, h. 26). Untuk itu perlu dikembangkan kegiatan pariwisata yang bermanfaat untuk pengembangan kualitas hidup secara berkelanjutan. Belakangan ini, salah satu kegiatan yang paling banyak dibicarakan dalam kegiatan pariwisata, bahkan telah menjadi isu global, yaitu ecotourism atau ekowisata sebagai kegiatan wisata alam yang berdampak ringan terhadap lingkungan. Ekowisata dalam era pembangunan berwawasan lingkungan merupakan suatu misi pengembangan wisata alternatif yang tidak menimbulkan banyak dampak negatif, baik terhadap lingkungan maupun terhadap kondisi sosial budaya (Dinas Kebudayaan dan Pariwisata Kabupaten Malang, 2013, h. I-4). Sudah waktunya pola wisata masyarakat diarahkan pada pariwisata yang berwawasan lingkungan dibandingkan dengan pariwisata bentuk lama (konvensional) yang kurang mengindahkan prinsipprinsip konservasi, sehingga terjadi eksploitasi yang terlalu berlebihan yang berakibat pada degradasi sumber daya alam.

Ekowisata memiliki ciri khas tersendiri, yaitu mengutamakan konservasi lingkungan, pendidikan lingkungan, kesejahteraan warga sekitar dan penghormatan terhadap budaya lokal. Akibat Industri pariwisata internasional telah berubah dari pariwisata massal menjadi pariwisata minat khusus, yaitu ekowisata (Nugroho, 2011, h. 3).

Ekowisata adalah bagian dari sustainable tourism atau wisata berkelanjutan, yaitu sektor ekonomi yang lebih luas dari ekowisata yang mencakup sektor-sektor pendukung kegiatan wisata secara umum, meliputi wisata bahari (beach and sun tourism), wisata pedesaan (rural and agro tourism), wisata alam (natural tourism), wisata budaya (cultural tourism), atau perjalanan bisnis (bussiness travel) (Nugroho, 2011, h. 15). Peraturan Menteri Dalam Negeri No. 33 Tahun 2009 tentang Pedoman Pengembangan Ekowisata di Daerah; juga memberikan pemahaman yang sama dalam memberikan pengertian ekowisata, yaitu kegiatan wisata alam di daerah yang bertanggung jawab dengan memperhatikan unsur pendidikan, pemahaman, dan dukungan terhadap usaha-usaha konservasi sumberdaya alam, serta peningkatan pendapatan masyarakat lokal.

Pada Tahun 2013, Pemerintah Kabupaten Malang memperoleh dukungan dari Direktorat Jenderal Bina Pembangunan Daerah, Kementerian Dalam Negeri pada Tahun Anggaran 2013 berupa alokasi kegiatan berupa Tugas Pembantuan Pengelolaan dan Pengembangan Kawasan Ekowisata Berbasis Masyarakat (PPKE-BM) bersumber dari Anggaran Pendapatan dan Belanja Negara (APBN) dalam melaksanakan pembangunan kawasan ekowisata dengan fokus pengembangan pada areal lahan Taman Buah Jeru di Desa Jeru, Kecamatan Tumpang. Taman Buah Jeruk seluas 11,7 Ha sebelumnya adalah obyek wisata Taman Burung Jeru yang dibangun pada Tahun 1998 dan untuk pengelolaannya dipercayakan kepada Perusahaan Daerah Jasa Yasa melalui Surat Keputusan Bupati Malang Nomor 11 Tahun 1998 Tanggal 16 Pebruari 1998 tentang Penunjukkan Perusahaan Daerah Jasa Yasa Kabupaten Malang sebagai Pengelola Asset Daerah Percontohan Mini Pelestarian Identitas Flora dan Fauna Kabupaten Daerah Tingkat II Malang di Desa Jeru Kecamatan Tumpang. Namun pada Tahun 2003 sesuai dengan Surat Direksi Perusahaan Daerah Jasa Yasa Nomor: 556/234/429.401/2003 tanggal 6 Juni 2003, Perusahaan Daerah Jasa Yasa mengalihkan kembali pengelolaan Unit Wisata Taman Buah Jeru Kecamatan Tumpang kepada Pemerintah Kabupaten Malang karena berdasarkan hasil audit Akuntan Publik, Dokumen Aliran Kas 2002 dan 2003 serta Hasil Rapat Kerja antara Perusahaan Daerah Jasa Yasa dengan Komisi C DPRD Kabupaten Malang tanggal 29 Mei 2003 diperoleh pertimbangan bahwa Taman Burung Jeru belum memberikan keuntungan serta tidak ada keseimbangan antara penerimaan dan pengeluaran atau dengan kata lain tidak menghasilkan pendapatan dan hanya mengeluarkan biaya perawatan.

Pengelolaan potensi ekowisata Taman Buah Jeru masih belum optimal dalam memberikan kontribusi terhadap peningkatan pendapatan daerah serta kesejahteraan masyarakat. Hal ini disebabkan dalam perencanaan pengembangannya terdapat hambatan atau kekurangan teknis maupun non teknis yang dipandang tidak signifikan, tetapi pengaruhnya terhadap proses dan keluaran perencanaan itu sendiri sangat besar sehingga alternatif-alternatif tindakan yang dipilih masih belum dapat digunakan sebagai jalan keluar atau solusi atas permasalahan yang ada. Perencanaan pengelolaan kawasan ekowisata yang dilakukan masih bersifat 
sektoral dan belum terintegrasi dengan seluruh komponen yang terkait, sehingga belum ada sinergi antara pemangku kepentingan, program kegiatan dan sumber daya untuk pengembangannya.

\section{Teori}

Menggunakan model proses perencanaan menurut Conyers \& Hills (1990, h. 74-75), yaitu sebagai berikut:

\subsection{The Decision to Adopt Planning}

Keputusan awal untuk menjadikan perencanaan sebagai alat untuk memecahkan masalah pembangunan dalam mencapai tujuan dan sasaran yang diinginkan. Pada tahap ini tentukan kerangka organisasinya (tentukan tujuan dan pengembangan rencana).

\subsection{Collect and Analyse Data}

Pada tahap ini, diperlukan analisis situasi untuk menentukan sifat dan masalah dari rencana tersebut. Pengumpulan dan analisis data adalah bagian dari identifikasi masalah dan membutuhkan sumber daya keuangan, tenaga kerja yang terlatih, serta akses ke berbagai fasilitas.

\subsection{Identifying Alternatives Course of Action}

Tentukan tindakan untuk alternatif dan langkahlangkah yang layak untuk memecahkan masalah dalam mencapai tujuan pembangunan yang diinginkan.

\subsection{Plan and Project Appraisal}

Pada hakikatnya, ini berarti mengidentifikasi kelebihan dan kekurangan yang dirancang untuk menargetkan setiap pemberian informasi kepada pengambil keputusan dalam membantu mereka memutuskan tindakan yang akan diambil.

\subsection{Implement}

Hal ini dianggap sebagai hal yang berada diluar ruang lingkup rencana, karena pelaksanaan rencana tersebut tanggung jawab operasional teknis dan administratif. Namun realisasinya tidak lepas dari tahapan yang lain. Oleh karena itu, sangat penting dalam memperhatikan pelaksanaan, menentukan berbagai jenis kegiatan yang berkaitan dengan rencana atau proyek, dan mengembangkan rencana lain mengenai sumber daya (keuangan, kepegawaian, material, dan peralatan).

\subsection{Monitoring and Evaluation}

Saat melaksanakan proyek, penting untuk memantau serta mengevaluasi dalam rangka mengidentifikasi beberapa masalah yang mungkin timbul dan untuk mengetahui apakah kegiatan tersebut sejalan dengan rencana yang ada.

\section{Metode Penelitian}

Jenis penelitian yang dipakai adalah penelitian dengan pendekatan kualitatif. Penelitian yang dilakukan bersifat deskriptif, yaitu suatu metode penelitian yang bertujuan untuk mendeskripsikan fenomena yang ada dan terjadi sekarang maupun di masa lalu. Penelitian ini mengungkapkan permasalahan apa adanya sesuai dengan kenyataan dilapangan karena peneliti memperoleh gambaran yang bersifat komprehensif dan mendalam mengenai perencanaan ekowisata dan pelaksanaannya di Kabupaten Malang.

Pada penelitian ini, peneliti memperoleh data melalui tiga kegiatan, yakni observasi yang dilaksanakan di Taman Buah Jeru di Desa Jeru, Kecamatan Tumpang; Wawancara mendalam dengan narasumber dari Kepala Bidang Perencanaan Ekonomi Badan Perencanaan Daerah Kabupaten Malang; serta Kepala Bidang Obyek Wisata Dinas Kebudayaan dan Pariwisata Kabupaten Malang. Kemudian subyek terkait yang berasal dari Dinas Kehutanan Kabupaten Malang dan Dinas Pertanian dan Perkebunan Kabupaten Malang, perangkat Desa Jeru dan aparat Kecamatan Tumpang serta masyarakat sekitar yang terlibat dalam serta dengan dokumentasi.

\section{Hasil Penelitian dan Pembahasan}

\subsection{The Decision to Adopt Planning}

Dari analisa fungsi kawasan yang dilakukan oleh Badan Perencanaan Daerah Kabupaten Malang (2007), menunjukkan potensi-potensi wisata yang dapat dikembangkan di Kawasan Jeru, yaitu dalam pengembangan fasilitas dapat dipertimbangkan kelompok sasaran yang dibedakan antara anak-anak, remaja dan dewasa. Kelompok anak-anak sangat potensial karena berdasarkan sifat-sifatnya akan selalu diikuti oleh orang yang lebih dewasa sedangkan kelompok remaja juga potensial karena kunjungannya sering berombongan dengan teman sebayanya. Dengan demikian fasilitas wisata yang dikembangkan adalah yang mempunyai tantangan tetapi aman bagi anak-anak, petualangan alam dan buatan sesuai dengan karakter remaja serta rekreasi yang memberikan kesegaran jasmani maupun rohani bagi kelompok yang lebih dewasa. Kebijakan penetapan wilayah ekowisata telah melalui hasil riset dan studi kelayakan yang dilakukan pusat dan dari perguruan tinggi yang telah ditunjuk. Sedangkan dari sumber- sumber yang diperlukan berupa tenaga, biaya, bahan dan peralatan sudah tercakup kedalam hasil studi kelayakan yang telah dilakukan sebelumnya.

\subsection{Collect and Analyse Data}

Proses perencanaan merupakan tahapan yang terstruktur, dimulai dari tahapan pengumpulan data, 
pemilahan informasi, perumusan kebutuhan, evaluasi anggaran, pengambilan keputusan, keputusan pelaksanaan, pengendalian pelaksanaan, pemantauan dan evaluasi hasil, pelaporan, dan analisis dampak, hingga menjadi sebuah siklus. Langkah-langkah ini merupakan faktor kunci untuk berhasil mencapai tujuan rencana pembangunan (Wrihatnolo \& Riant, 2006 h. 57- 59). Kalau melihat pendapat tersebut, perencanaan pembangunan kawasan ekowisata Taman Buah Jeru di Kabupaten Malang, beberapa asumsi telah terpenuhi, seperti keputusan kepala daerah dan perencanaan sudah dilakukan sesuai prosedur melalui tahapan-tahapan baik bottom up maupun top down. Kemudian mengenai sumber daya yang tersedia di Kabupaten Malang dalam rangka pembangunan Kawasan Ekowisata Taman Buah Jeru, seperti potensi wisata alam dengan daya dukungnya akan diatur supaya bisa memenuhi ketentuan manajemen dan pengelolaan konsep ekowisata Taman Buah Jeru agar bisa untuk memenuhi kebutuhan pembangunan. Sedangkan mengenai prosedur perencanaan dalam pembangunan Kawasan Ekowisata Taman Buah Jeru di Kabupaten Malang, dimana prosedur yang merupakan langkah terstruktur sudah ada dimulai dari langkah pengumpulan data yang dilakukan para peneliti, penyiapan informasi, perumusan kebutuhan, evaluasi anggaran, pengambilan keputusan dan pelaksanaan keputusan telah dilakukan.

\subsection{Identyfling Alternatives Course of Action}

Menurut Damanik \& Weber (2006, h. 49) perencanaan ekowisata terkait dengan pengembangan produk pariwisata. Setiap daerah perlu menilai kembali potensi wisata dan produk yang ada, kemudian membuat rencana yang tepat tentang bagaimana mengembangkan potensi tersebut dan bagaimana merancang produk yang ada untuk memenuhi kebutuhan pasar. Berdasarkan pendapat tersebut diketahui bahwa untuk tahapan awal suatu perencanaan berupa penyusunan rencana yang terdiri dari beberapa unsur antara lain berupa tinjauan keadaan, yang merupakan tinjauan keadaan suatu daerah sebelum memulai sesuatu rencana atau tinjauan tentang keadaan daerah dimana sudah terjadi pelaksanaan rencana sebelumnya. Oleh sebab itu, didalam perencanaan pembangunan Kawasan Ekowisata Taman Buah Jeru di Kabupaten Malang; unsur tentang tinjauan keadaan daerah ini sudah dilakukan, dimana kondisi dari sebelum perencanaan pembangunan ekowisata Taman Buah Jeru dengan keadaan masih pemula dan masih terbatas kondisinya. Sedangkan untuk tahapan penyusunan rencana, yaitu penetapan maksud atau tujuan secara lebih rinci dalam kurun waktu tertentu, rincian jadwal kegiatan, jumlah dan jadwal pembiayaan, serta penetapan lembaga atau kerjasama antar lembaga mana yang akan melakukan program, dapat dilihat bahwa dalam pembangunan kawasan ekowisata Taman Buah
Jeru di Kabupaten Malang memiliki jadwal kegiatan dan telah dilaksanakan.

\subsection{Plan and Project Appraisal}

Korporasi sebegai implementor menanggapi kebijakan mengenai CSR dalam perencanaan pembangunan kawasan ekowisata Taman Buah Jeru di Kabupaten Malang penentuan kelayakan didasarkan beberapa aspek yang telah ditentukan standar nilainya sendiri yang sudah ditetapkan dari Kementerian Dalam Negeri. Keadaan yang mana dokumen hasil studi kelayakan belum tercantum dalam perencanaan pembangunan Kawasan Ekowisata Taman Buah Jeru Kabupaten Malang terjadi dikarenakan antara lain: (a) Perencanaan ini menyangkut dana yang besar yang berada di tangan SKPD pelaksana tertentu; (b) Penelitian yang dilaksanakan secara cepat atau buru-buru, sehingga hasilnya kurang maksimal keakuratannya, seperti dalam hal penjaringan data lokasi ekowisata sehingga dapat mengakibatkan ketidaktepatan sasaran dana; (c) Penelitian yang dilaksanakan sepertinya untuk mencukupi persyaratan agar pendanaan cepat segera turun, sehingga tim ahli kurang cermat dalam pembuatan dokumen hasil studi kelayakan yang terabaikan; serta (d) Kurang kontrol pengawasan dari pihak pemerintah daerah sendiri pada saat awal proses perencanaan, sehingga mengakibatkan kekurangan dokumen hasil studi kelayakan yang baru diketahui setelah rencana kegiatan dilaksanakan. Untuk itu karena dalam perencanaan pembangunan ekowisata Taman Buah Jeru membutuhkan dana yang sangat besar, sehingga studi kelayakan sangat diperlukan agar dapat menghindari adanya resiko kerugian karena ketidaktepatan suatu perencanaan usaha yang kurang matang.

\subsection{Implement, Monitoring and Evaluation}

Meskipun pelaksanaan pembangunan kawasan ekowisata Taman Buah Jeru di Kabupaten Malang sudah lebih dari empat tahun tetapi pada kenyataannya masih banyak kegiatan yang belum dilaksanakan secara optimal, seperti masih banyaknya hasil fisik pembangunan yang telah selesai dilaksanakan namun masih belum dapat dimanfaatkan karena belum adanya kepastian pengelolaan yang dapat menghasilkan pemasukan sebagai sumber Pendapatan Asli Daerah (PAD).

Dengan proses pelaksanaan pembangunan Kawasan Ekowisata Taman Buah Jeru di Kabupaten Malang ini dapat disimpulkan sesuai dengan model perencanaan Conyers \& Hills pada bagian implement, yaitu bahwa pelaksanaan rencana menjadi tanggung jawab teknis dan administrasi operasional. Namun, implementasi tidak lepas dari tahapan lainnya serta monitoring and evaluation, yaitu ketika terdapat monitoring dan evaluasi atas implementasi rencana atau proyek untuk 
mengidentifikasi beberapa masalah yang mungkin terjadi dan mengetahui apakah kegiatan tersebut sesuai dengan perencanaan.

\section{Kesimpulan}

Berdasarkan hasil penelitian dan pembahasan terhadap fokus permasalahan dalam penelitian ini, maka dapat ditarik beberapa kesimpulan sebagai berikut:

a) Perencanaan pembangunan ekowisata Taman Buah Jeruk Kabupaten Malang merupakan perpaduan antara perencanaan top down serta perencanaan bottom up. Dimana perencanaan top down merupakan perencanaan yang telah dibuat dan ditetapkan dari pusat dalam hal ini Kementerian Dalam Negeri, sedangkan perencanaan bottom up dilakukan pemerintah Kabupaten Malang yang diwujudkan dalam bentuk pembuatan masterplan ekowisata. Sumber daya manusia tersedia, sumber dana telah diatur oleh pemerintah dan perusahaan, dan pelaksanaan kegiatan CSR tidak memiliki batas waktu;

b) Daerah dalam pembuatan perencanaan pembangunan Kawasan Ekowisata Taman Buah Jeru Kabupaten Malang sebelumnya harus mempersiapkan antara lain: sumber daya manusia, teknologi, sarana prasarana, serta modal;

c) Untuk dapat menjadi lokasi pembangunan kawasan ekowisata terlebih dahulu melalui studi kelayakan yang dilakukan oleh pemerintah daerah didampingi pihak Kementerian Dalam Negeri yang diambil antara lain dari sisi potensi sumber daya alam serta sumber daya manusia, akan tetapi dalam hal dokumen hasil studi kelayakan di Kabupaten Malang belum ada;

d) Pembiayaan pembangunan ekowisata Taman Buah Jeru di Kabupaten Malang berasal dari beberapa sumber antara lain Dana Tugas Pembantuan (TP) (APBN) pusat serta APBD kabupaten;

e) Stakeholder dalam perencanaan pembangunan ekowisata Taman Buah Jeru di Kabupaten Malang terdiri dari: perguruan tinggi, SKPD, masyarakat, bupati; serta DPRD; dan

f) Faktor pendukung internal: status lahan milik pemerintah, aksesibilitas tinggi, potensi dan daya tarik cukup lengkap; dukungan dari pemerintah melalui Dinas Pariwisata Kabupaten Malang: ketersediaan SDM. Adapun faktor pendukung eksternal: berada dijalur wisata, yaitu Taman Nasional Bromo Tengger Semeru. Faktor penghambat internal: akses masuk melewati perkampungan dengan lebar jalan relatif sempit, potensi wisata belum dieksplorasi, isu permasalahan dan konflik lebih menonjol, lemahnya ilmu pengetahuan dan teknologi, kurangnya SDM, lemahnya koordinasi, integrasi, dan sinkronisasi antar sektor, pengelolaan belum optimal, serta sulitnya sumber air bersih. Kemudian Faktor eksternal: ancaman biaya pemeliharaan habitat satwa yang mahal, tingginya tingkat kerawanan kawasan, tingkat pendidikan masyarakat sekitar rendah, kondisi perekonomian masyarakat yang sangat bergantung pada SDA kawasan, kebijakan investasi yang tidak menarik bagi investor, kebutuhan lahan untuk kawasan tinggi, serta daya dukung lingkungan terbatas.

\section{Daftar Pustaka}

Conyers, Diana., \& Peter Hills. (1990). Introduction to Development Planning in The Third World. John Wiley \& Sons Chichester, New York.

Damanik J., \& Weber HF. (2006). Perencanaan Ekowisata: Dari Teori ke Aplikasi. Yogyakarta, CV. Andi Offset.

Dinas Kebudayaan dan Pariwisata Kabupaten Malang. (2013). Laporan Akhir Penyusunan Masterplan Ekowisata Kabupaten. Malang: Dinas Kebudayaan dan Pariwisata Kabupaten Malang.

Nugroho, Iwan. (2011). Ekowisata dan Pembangunan Berkelanjutan. Yogyakarta: Pustaka Pelajar.

Ramly, Nadjamuddin. (2007). Pariwisata Berwawasan Lingkungan: Belajar dari Wisata Ancol. Jakarta: Grafindo Khazanah llmu.

Wrihatnolo, Randy R., \& dan Riant, Nugroho. (2006). Manajemen Pembangunan Indonesia: Sebuah Pengantar dan Panduan. Elex Media Komputindo, Jakarta. 